\title{
PENGEMBANGAN LKS BERDASARKAN EKSPLORASI TANAMAN OBAT SUKU PEKAL PADA MATERI KEANEKARAGAMAN HAYATI
}

\author{
Herlina Rahayu $^{1 *}$, Ariefa P. Yani ${ }^{1}$, Irdam Idrus ${ }^{1}$ \\ ${ }^{1}$ Program Studi Pendidikan Biologi, Fakultas Keguruan dan Ilmu Pendidikan, Universitas Bengkulu \\ Email: herlinarahayu10@gmail.com
}

\begin{abstract}
ABSTRAK
Penelitian ini bertujuan untuk membuat LKS berdasarkan eksplorasi tanaman obat suku Pekal Desa Bukit Indah Kecamatan Ketahun Kabupaten Bengkulu Utara. Sub bab pada desain LKS yang dibuat pada pembelajaran biologi ini yaitu sub materi keanekaragaman hayati tingkat spesies dan diujicobakan pada siswa kelas X SMAN 1 Ketahun. Jenis penelitian ini adalah penelitian dan pengembangan. Motede penelitian yang digunakan adalah $R$ \& D dengan langkah utama Borg and Gall yang telah dimodifikasi. Yang mana langkah-langkahnya yaitu potensi dan masalah, pengumpulan data, desain produk, validasi desain, revisi desain dan uji coba produk. Instrumen pengumpulan data yang digunakan terdiri dari lembar observasi lapangan, lembar wawancara, lembar angket validasi ahli dan tes. Berdasarkan hasil penelitian yang telah dilakukan, jenis tanaman obat yang temukan berjumlah 44 jenis dengan 25 famili. LKS yang dikembangan dari eksplorasi tanaman obat mendapatkan katagori "sangat baik" oleh validator dan layak digunakan dalam pembelajaran Biologi sub materi keanekaragaman jenis kelas X SMAN 1 Ketahun. Hasil belajar siswa mencapai ketuntasan secara klasikal dengan presentase $90,47 \%$ dan dinyatakan tuntas.
\end{abstract}

Kata kunci: Lembar Kerja Siswa (LKS), Tanaman obat, Hasil Belajar Siswa

\section{ABSTRACT}

This study aims to create LKS based on the exploration of medicinal plants in Pekal Village Bukit Indah Village Ketahun District North Bengkulu Regency. The sub-chapters on the LKS designs made in this biology learning are sub-species biodiversity level biodiversity and are tested in X-class students of SMAN 1 Ketahun. The research motive used is R \& D with the main step of Borg and Gall that has been modified. Which steps are potential and problems, data collection, product design, design validation, design revisions and product testing. The data collection instruments used consist of field observation sheets, interview sheets, expert validation questionnaires and tests. Based on the results of research that has been done, the type of medicinal plants that found amounted to 44 species with 25 families. LKS developed from the exploration of medicinal plants get the category "very good" by the validator and feasible to be used in learning Biology sub-material class X-type diversity SMAN 1 Ketahun. Student learning outcomes achieve mastery by classical with percentage $90,47 \%$ and expressed completely.

Keywords: Student Worksheet (LKS), Medicinal plants, Student Learning Results

\section{PENDAHULUAN}

Pendidikan pada hakikatnya adalah
proses pematangan kualitas hidup.
Melalui proses tersebut diharap manusia
dapat memahami apa arti dan hakikat
hidup, serta untuk apa dan bagaimana
menjalankan tugas hidup dan kehidupan
secara benar. Karena itulah fokus
pendidikan diarahkan pada pembentukan

kepribadian unggul dengan menitikberatkan pada proses pematangan kualitas logika, hati, akhlak, dan keimanan. Puncak pendidikan adalah tercapainya titik kesempurnaan kualitas hidup (Mulyasana, 2012).

Dalam konteks ini, maka tujuan pendidikan adalah sebagai penuntun, pembimbing, dan petunjuk arah bagi para peserta didik agar mereka dapat tumbuh dewasa sesuai dengan potensi dan konsep 
diri yang sebenarnya, sehingga mereka dapat tumbuh, bersaing, dan mempertahankan kehidupannya di masa depan yang penuh dengan tantangan dan berubah. Untuk mewujudkan dari tujuan pendidikan tersebut maka seorang tenaga pendidik dituntut untuk meracang pembelajaran semenarik mungkin. Upaya untuk mencapai tujuan tersebut adalah dengan mengembangkan suatu bahan ajar yang inovatif. Bahan ajar yang dapat dikembangkan salah satunya adalah Lembar Kerja Siswa (LKS) (Mulyasana, 2012).

LKS adalah panduan siswa yang digunakan untuk melakukan kegiatan penyelidikan atau pemecahan masalah. LKS dapat berupa panduan untuk latihan pengembangan aspek kognitif maupun untuk pengembangan semua aspek pembelajaran dalam bentuk panduan eksperimen atau demostrasi. LKS memuat sekumpulan kegiatan dasar yang harus dikerjakan oleh siswa untuk memaksimalkan pemahaman dalam upaya pembentukan kemampuan dasar sesuai indikator pencapaian hasil belajar yang harus ditempuh (Trianto, 2012).

Bahan ajar LKS sangat cocok jika digunakan dalam pembelajaran Biologi SMA. Karakteristik LKS bersifat sistematis, runut dan mampu menjadikan materi Biologi yang rumit menjadi sederhana. Guru dapat menyusun dan mengembangkan LKS disesuaikan dengan kebutuhan serta keadaan sekolah. Setiap sumber belajar biologi didampingi dengan bahan ajar LKS untuk menyederhanakan materi pembelajaran serta melatih keterampilan proses dasar siswa. Pembelajaran biologi akan menjadi lebih menarik, karena contoh-contoh yang diambil untuk dikembangkan dalam LKS sangat dekat dengan kehidupan seharihari siswa dan bersifat kontekstual.

Berdasarkan pengalaman peneliti dan wawancara terhadap guru biologi serta beberapa siswa SMAN 1 Ketahun, penggunaan LKS hasil inovasi guru jarang sekali digunakan. Beberapa sumber belajar seperti buku paket dan LKS yang diberikan pihak sekolah atau dari penerbit menjadi pilihan utama dalam kegiatan pembelajaran, dengan kata lain guru belum menggunakan LKS yang didesain dengan memanfaatkan lingkungan sekitar sebagai sumber informasi pembuatan bahan ajar. Seperti yang diketahui bahwa lingkungan sekitar SMAN 1 Ketahun dihuni oleh masyarakat suku pekal. Yang mana masyarakatnya masih kental terhadap pemanfaatan tanaman obat yang ada di sekitar pekarangan rumahnya. Dengan memperoleh infomasi dan observasi langsung tanaman obat yang ada maka dapat berpotensi untuk dijadikan sumber belajar.

Menurut sumber data dari kantor kecamatan Ketahun luas wilayah desa Bukit Indah yaitu 102 hektar. Desa Bukit Indah terdapat pada pinggiran sungai Ketahun yang menjadikan wilayah tersebut banyak kandungan kadar air sehingga banyak jenis tanaman yang dapat tumbuh subur di sekitar lingkungan rumah. Melimpahnya jenis tanaman tesebut banyak dimanfaatkan masyarakat suku pekal sebagai obat tradisional. Tanaman obat merupakan jenis tanaman yang berkhasiat guna menyembuhkan berbagai penyakit. Jenis tanaman obat ini sangat banyak, ada yang berhabitus pohon semak, herba, epifit bahkan ada yang satu suku misalnya suku Zingiberaceae. Dari banyaknya jenis tersebut, maka dapat dikembangkan menjadi sebuah bahan ajar yang sesuai dengan salah satu materi yaitu keanekaragaman hayati yaitu keanekaragaman jenis. Ini sesuai dengan KD 3.1 Mendeskripsikan konsep keanekaragaman gen, jenis, ekosistem, melalui kegiatan pengamatan.

Untuk mendapatkan LKS yang baik dan selaras dengan tujuan kompetensi dasar siswa, maka dilakukan 
pengembangan LKS dengan metode penelitian pengembangan model Bord and Gall. Pemilihan metode ini dikarenakan metode ini bertujuan untuk memvalidasi dan mengembangkan produk-produk efektif seperti bahan ajar, media pembelajaran dan materi ajar yang dapat digunakan dalam pembelajaran (Sugiyono, 2016).

\section{METODE PENELITIAN}

Jenis penelitian ini adalah penelitian dan pengembangan. Menurut Sugiyono (2016), model penelitian pengembangan dapat diartikan sebagai cara ilmiah untuk meneliti, merancang, memproduksi dan menguji validitas produk yang telah dihasilkan. Metode penelitian yang digunakan dalam penelitian ini, yaitu metode Borg and Gall yang dimodifikasi oleh Sugiyono.

Subjek penelitian merupakan sesuatu yang penting kedudukannya

Teknik analisis data hasil observasi data hasil pengamatan tumbuhan obat yang diperoleh dianalisis deskriptif. Menurut Arikunto (2013).

Teknik analisis data hasil wawancara dilakukan pada guru biologi dan siswa untuk memperoleh informasi mengenai LKS yang digunakan

Keterangan:

$$
\mathrm{P}=\frac{\sum x}{\sum x i} x 100 \%
$$

Tabel 3.1. Kriteria Validitas LKS

\begin{tabular}{ccc}
\hline Persentase $\%$ & Kriteria Validitas & Keterangan \\
\hline $81,25-100$ & Sangat valid & Layak/Tidak revisi \\
$62,50-81,24$ & Valid & Cukup layak/Tidak revisi \\
$43,75-62,49$ & Kurang valid & Kurang layak/ revisi sebagian \\
$25-43,74$ & Sangat kurang valid & Tidak layak/revisi total \\
\hline
\end{tabular}

Data hasil belajar siswa dianalisis dengan rerata, standar deviasi, persentase kategori ketuntasan dari skor seluruh siswa. Rerata digunakan untuk menganalisis ketercapaian hasil belajar secara umum yang bisa digambarkan. Rerata skor hasil belajar menggunakan rumus (Sukardi, 2012) : dalam penelitian. Subjek penelitian dapat berupa benda, hal atau orang. Subjek penelitian ini adalah siswa kelas X SMAN 1 Ketahun Kabupaten Bengkulu utara. Variabel penelitian ini adalah LKS, tanaman obat suku pekal, hasil belajar siswa. Teknik pengumpulan data pada penelitian ini adalah observasi, wawancara, angket, dan lembar tes.

Prosedur penelitian dilaksanakan dengan mengacu pada langkah-langkah penelitian Borg and Gall (1989) dalam Sugiyono (2011) yang telah dimodifikasi. Adapun langkah-langkahnya sebagai berikut :
a. Potensi dan masalah
b. Mengumpulkan informasi
c. Desain Produk
d. Validasi produk
e. Perbaikan desain
f. Uji coba produk

$\mathrm{P} \quad=$ presentasi kevalidan

$\sum x i=$ jumlah nilai ideal per item

$\sum x=$ jumlah jawaban responden per item

$100 \%=$ konstanta

Hasil analisis data yang berupa persentase tersebut kemudian dicocokan dengan kriteria kevalidan (tabel 3.1). Kemudian akan dijadikan dasar dilakukan layak atau tidak LKS tersebut diujicobakan.
$\bar{X}=\frac{\sum X}{N}$

Keterangan:

$\bar{X}=$ Rata-rata skor hasil belajar siswa;

$\sum x=$ Jumlah skor hasil belajar siswa

$\mathrm{N}=$ Jumlah siswa kelas $\mathrm{X}$ SMAN 1 Ketahun 
Persentase digunakan untuk menggambarkan proporsi tuntas atau tidak tuntasnya hasil belajar siswa. Persentase ketuntasan belajar dihitung dengan rumus :

$\mathrm{KB}=\frac{N S}{N} x 100 \%$

Keterangan:

$\mathrm{KB}=$ Persentase ketuntasan belajar

NS = Jumlah siswa yang mendapat nilai $\geq 75$

$\mathrm{N}=$ Jumlah siswa

(Berdasarkan ketentuan di SMAN 1 Ketahun).

\section{HASIL DAN PEMBAHASAN}

1. Hasil

a. Jenis-jenis tanaman yang

dimanfaatkan sebagai obat oleh

masyarakat Suku Pekal desa Bukit

Indah Kecamatan Ketahun
Dari hasil penelitian yang telah dilakukan di desa Bukit Indah kecamatan Ketahun diperoleh 44 jenis tanaman obat yang terdiri dari 25 famili. Tanaman obat tersebut dimanfaatkan sebagai obat oleh masyarakat desa Bukit Indah kecamatan Ketahun untuk mengobati suatu penyakit, data ini diperoleh berdasarkan hasil wawancara dan hasil eksplorasi peneliti dengan 3 orang battra

Tabel 4.1. Jenis-jenis tumbuhan obat yang dimanfaatkan oleh masyarakat Suku Pekal Desa Bukit Indah Kecamatan Ketahun Kabupaten Bengkulu Utara

\begin{tabular}{|c|c|c|c|c|}
\hline No & $\begin{array}{c}\text { Famili/ Nama } \\
\text { Ilmiah } \\
\text { / Nama } \\
\text { Indonesia/ Nama } \\
\text { Lokal }\end{array}$ & $\begin{array}{c}\text { Organ } \\
\text { Tumbuhan } \\
\text { Yang } \\
\text { Dimanfaat } \\
\text { Kan }\end{array}$ & $\begin{array}{c}\text { Manfaat Sebagai } \\
\text { Obat }\end{array}$ & Habitus \\
\hline
\end{tabular}

1. Acanthaceae
a. Graptophyllum pictum/puding abang/daun pihung
b. Strobilanthes crispus/keji beling
c. Andrographis paniculata/
Daun
Bengkak dan memar
Perdu
Daun
Daun
Batu ginjal
Semak
Malaria, tipus,
Herba Sambiloto

2. Annonaceae
a. Anona muricata/sirsak/ sarikayo
Daun, Buah
Ambeien, mencret
Pohon pada bayi, bisul, sakit pinggang

3. Apiaceae
a. Apium graveolens/Seledri

Daun, batang
Hipertensi, mata kering

4. Arecaceae
a. Cocos nucifera/ Kelapa hijau/ niur
b. Areca catechu/Pinang / bakak

Buah

Biji
melancarkan menstruasi, panas dalam
Kudis, korengan, cacingan

5. Asterraceae

a. Pluchea indica/Beluntas/luntas
Daun, batang, akar

Menghilangkan bau badan, TBC, rematik

Herba

Pohon

6. Bromeliaceae 

a. Ananas comusus/ Nanas
Buah, daun
Amandel, luka bakar, bisul
Herba

7. Caricaceae
a. Carica papaya/Papaya/sapilo
Daun, akar, buah
Malaria, hipertensi,
Pohon
sembelit,

8. Cucurbitaceae
Daun, buah, biji, akar

b. Cucumis sativus/Timun/lepang

Buah

Obat

Liana

cacing, diabetes, diare, menyuburkan rambut, Menurunkan

Liana

9. Euphorbiaceae
a. Jatropa curcas/Jarak pagar
Daun, biji,
b. Sauropus androgynous/ Katuk
Daun, akar

Obat gatal, perut kembung

Penambah ASI, air kencing sedikit

10. Lamiaceae
a. Ocinum sactum/ Kemangi
b. Ortoshipon spicatus/Kumis kucing

\section{Daun \\ Daun, bunga \\ Daun \\ Umbi \\ Daun}

Bau mulut

Sakit pinggang, obat kencing sakit, batu ginjal, rematik

11. Lagumina
a. Cassia alata/Ketepeng

Malaria

Perdu

12. Liliaceae
a. Allium cepa/Bawang merah
b. Aloe vera/Lidah buaya

13. Malvaceae

a. Hibiscus radiatus/Rosella

14. Meliaceae
a. Swietenia mahagoni/Mahoni

15. Menispermae
a. Tinospora crispa/Brotowali

$$
\begin{gathered}
\text { Perut kembung } \\
\text { anak-anak }
\end{gathered}
$$

Rambut rontok, luka Herba bakar ringan

Bunga

Menurunkan

Semak tekanan darah

Biji

Malaria

Pohon

Koreng, gatal-gatal, luka ringan

Liana

16. Mimosaceae
a. Leucaena glauca/ petai cina/ lamtoro
Biji, daun
Cacingan, luka baru disertai bengkak
Perdu

17. Moringaceae
a. Moringa oleivera/ Daun kelor

Daun, tangka

Rematik, sakit kuning

Pohon daun

18. Mytraceae
a. Syzgium aromaticum/Cengkeh/ cakeh
b. Syzygium polyanthum/Daun salam
c. Psidium guajava/Jambu biji/ jambui biji

Biji

Campak

Pohon

Daun, kulit batang, akar
Menurunkan tekanan darah, maag, kudis
Diare, sariawan

Daun, buah

Pohon

Pohon 

a.Averrhoa bilimbii/ Belimbing wuluh/galimbing

20. Piperaceae
a. Piper nigrum/ Lada/ sahang
b. Piper betle/ Sirih hijau/daun iban
c. Piper crocatum/Sirih merah/ iban sirah

$$
\begin{aligned}
& \text { Buah } \\
& \text { Daun } \\
& \text { Daun }
\end{aligned}
$$

21. Poaceae
a. Imperata cilindrica/ Alang-alang/ lalang
b. Cymbopogom nardus/Serai/ sehai
c. Saccharum officinarum/Tebu hitam/ tebui

22. Rubiaceae
a. Morinda citrifolia/Mengkudu/ makodui

23. Rutaceae
a. Citrus aurantifolia/Jeruk nipis/ limau

24. Solanaceae
a. Datura metel/ Kecubung/ cubung
Daun
b. Solanum torvum/Kecombrang/ tehung imbang

25. Zingiberaceae
a. Zingiber officinale/Jahe
b. Kaempfeia galangal/Kencur
c. Curcuma domestica/Kunyit/ kunyik
d. Alpinia galangal/Lengkuas
e. Curcuma xanthoriza/Temulawak
f. Curcuma aeruginosa/Temu Hitam
g. Zingiber purpureum/Bangle

Buah, daun

Akar

Batang

Batang

Buah

Buah

Buah

Rimpang

Rimpang

Rimpang

Rimpang

Rimpang

Rimpang

Rimpang
Batuk, panu, jerawat, pegel linu

Pohon

$\begin{array}{ll}\text { Kurap } & \text { Liana } \\ \text { Keputihan, mimisan, } & \text { Liana } \\ \text { radang selaput mata } & \\ \begin{array}{c}\text { Penurun tekanan } \\ \text { darah }\end{array} & \text { Liana }\end{array}$

Tekanan darah

Herba tinngi, luka ringgn

Terkilir dan memar

Herba

Obat batuk

Herba

Amandel, batuk,
demam

Obat batuk, jerawat

Pohon

$\begin{array}{lc}\begin{array}{c}\text { Kompres penurun } \\ \text { panas anak, asma, } \\ \text { ramatik } \\ \text { Rabun mata }\end{array} & \text { Perdu } \\ & \text { Perdu }\end{array}$
Batuk, penghangat Herba suhu badan, radang tenggorokan
Penambah nafsu makan anak, batuk, diare

Pelancar menstruasi Herba

$\begin{array}{cc}\text { Obat panu } & \text { Herba } \\ \text { Penambah nafsu } & \text { Herba } \\ \text { makan anak } & \end{array}$

Batuk berdahak dan Herba sesak napas

Masuk angin, sakit Herba

\section{b. Hasil desain LKS}

Hasil penelitian eksplorasi tanaman obat di Desa Bukit Indah Kecamantan Ketahun kemudian dikembangkan menjadi bahan belajar berupa LKS. Penyusunan dan pengembangan LKS memperhatikan prosedur dan struktur yang tepat. Hal ini bertujuan agar LKS dapat digunakan pada pembelajaran Biologi kelas $X$ materi keanekaragaman hayati, sub materi keanekaragaman tingkat Jenis. Hasil analisis kurikulum yang telah dilakukan, kompetensi dasar yang diharapkan mampu tercapai dengan menggunakan LKS ini adalah 3.1 
Mendeskripsikan konsep keanekaragaman gen, jenis, ekosistem, melalui kegiatan pengamatan.

Sebelum diujicobakan pada pembelajaran, LKS yang disusun dan dikembangkan sudah menjalani uji validitas oleh beberapa ahli. LKS divalidasi terlebih dahulu oleh satu dosen biologi dan dua guru biologi SMA. Dengan masing-masing memiliki presentase tersedia pada tabel berikut ini:

Tabel 4.2. Tabel presentase validasi LKS oleh ahli bahan ajar

\begin{tabular}{ccc}
\hline No & Validator & Presentase \\
\hline 1. & Validator 1 & $84,37 \%$ \\
2. & Validator 2 & $85,93 \%$ \\
3. & Validator 3 & $95,31 \%$ \\
\hline
\end{tabular}

Berikut ini merupakan desain LKS yang telah divalidasi oleh validator dengan struktur halaman depan (cover), judul, tujuan pembelajaran, konsep, prosedur kerja, hasil pengamatan, pertanyaan dan kesimpulan.

Halaman pertama yaitu cover LKS yang dibuat semenarik mungkin dengan memperhatikan beberapa komponen seperti judul LKS, nama anggota kelompok, kelas yang akan menggunakan LKS, gambar berbagai jenis tanaman obat mewakili keanekaragaman tingkat jenis, logo pendidikan yaitu gambar TUT WURI HANDAYANI, logo unib yang menunjukan penyusun masih dibawah naungan universitas dan nama penyusun.

Kemudian di halaman ke dua terdapat beberapa unsur yaitu : tujuan pembelajaran yang dikembangkan dari KD dan diselaraskan. materi/konsep keanekaragaman dengan memperkenalkan terlebih dahulu tentang suku pekal untuk memberikan informasi kepada siswa bahwa di lingkungan mereka sekolah dihuni oleh masyarakat suku pekal dengan potensi alam yang dapat dikembangkan menjadi sebuah bahan belajar.

Selanjutnya dihalaman 3 dan 4 dimasukan materi tentang keanekaragaman baik keanekaragaman tingkat gen, jenis maupun ekosistem serta di halaman 4 disertakan beberapa tipe dari bentuk daun dan bentuk akar guna membantu siswa dalam mengisi tabel yang ada di LKS dalam pengelompokan tanaman.

Lalu di halaman 5 terdapat prosedur kerja yang terdiri dari alat dan bahan yang digunakan beserta cara kerjanya. Kemudian di halaman 6 terdapat tabel hasil pengamatan yang harus diisi oleh peserta didik. Dimana penyususan tabel ini disesuaikan dengan tujuan pembelajran yang pertama yaitu siswa mampu menyebutkan nama tanaman beserta ciri-cirinya. Adapun cirri yang harus diisikan pada tabel meliputi nama tanaman, bentuk daun, bentuk batang dan bentuk akar.

Kemudian di halaman terakhir terdapat pertanyaan sebanyak 3 butir yang dikembangkan dari tujuan pembelajaran. Soal pertama disesuaikan dengan tujuan ke tiga. Yang mana siswa diminta mengelompokan jenis tanaman yang telah mereka sebutkan ciri-cirinya berdasarkan tabel sebelumnya. Soal ke dua disesuaikan dengan tujuan ke dua, dimana siswa dituntut mampu menjelaskan konsep keanekaragaman tingkat jenis berdasarkan pengamatan yang telah dilakukan dan soal ke tiga disesuaikan dengan tujuan ke empat yaitu siswa diharapan mampu menyebutkan manfaat dari bebagai tanaman yang telah ada saat pengamatan. Selajutnya pada bagian kesimpulan, diberikan kalimat pengantar untuk mempermudah siswa. Untuk desain LKS keseluruhan dapat dilihat pada lampiran.

\section{Pembahasan}

\section{a. Jenis-jenis tanaman obat suku Pekal}

Setelah dilakukan observasi mengenai data lokasi yang digunakan untuk mencari tanaman obat, maka dipilih desa Bukit Indah, Kecamatan Ketahun, Kabupaten Bengkulu Utara sebagai tempat pencarian tanaman obat karena mempertimbangkan daerah tersebut masih dilewati bantaran sungai Ketahun. Bantaran sungai ini ternyata menyimpan potensi keanekaragaman tanaman yang berkhasiat sebagai obat. Berdasarkan data pada tabel 4.1 diperoleh 44 
jenis tanaman obat dari 25 famili. Jenis tanaman obat yang banyak dimanfaatkan oleh masyarakat suku pekal desa Bukit Indah yaitu tanaman dari famili Zingiberaceae dengan jumlah 7 jenis.tanaman. Famili Zingiberaceae merupakan famili yang didominaasi oleh jenis tanaman habitus herba. Tanaman ini umumnya hidup ditempat yang banyak mengandung kadar air. Sehingga pada eksplorasi ini banyak ditemukan tanaman dari famili Zingiberaceae di sepanjang bantaran sungai Ketahun. Selain jenis tanaman dari famili Zingiberaceae. Pengobatan tradisional masih banyak diminati oleh masyarakat dikarenakan efek samping yang sidikit dibandingkan dengan pengobatan kimia. Menurut Putra (2016), pengolahan herbal relatif lebih aman digunakan dan tidak terlalu menyebabkan efek samping sebagaimana penggunaan obat sintetik yang diproduksi pabrik farmasi. Hal tersebut dikarenakan komposisi herbal masih dapat dicerna oleh tubuh. Selain itu, kompleksitas struktur dari sediaan herbal ternyata dapat meminimalkan efek samping yang ditimbulkan dari aksi farmatologis/ bagian aktif dari obat.

Kebanyakan cara pengobatan ini dilakukan dengan cara direbus lalu diminum air rebusannya. Selain itu satu tanaman obat tidak hanya digunakan untuk satu penyakit. Misalnya daun jarak untuk mengobati perut kembung dengan cara mengahangatkan daunnya di atas api lalu ditempelkan pada perut. Kemudian daunnya bisa birebus dicampur dengan sambilito digunakan mandi untuk obat gatal. Umumnya penggunaan tanaman obat ini dikombinasikan dengan bahan lain sesuai dengan petunjuk dari battra. Seiring meningkatnya kebutuhan masyarakat akan pengobatan yang aman, efektif, dan ekonimis, masyarakat mulai membudidayakan tanaman obat/herbal, baik dalam skala rumah tangga ataupun secara masal. Meskipun obat herbal relatif aman dibandingkan obat sintesis, akan tetapi tidak serta merta menghilangkan potensi munculnya efek samping yang dapat merugikan kesehatan. Kandungan herbal tentunya sama sengan kandungan yang ada pada obat-obatan sintetis. Beberapa hal yang perlu diperhatikan untuk meminimalkan efek yang tidak diinginkan yaitu harus mengetahui kandungan yang terdapat pada tanaman tesebut sehinggan dalam penggunaannya harus benar-benar sesuai dengan resep yang diberikan oleh battra atau orang yang sudah berpengalaman.

\section{b. Uji coba pengembangan LKS}

Pengembangan LKS mengikuti prosedur Prastowo (2011), meliputi desain, tujuan pembelajaran, materi, kegiatan siswa, pertanyaan dan struktur. Desian LKS dirancang dengan mengunakan kertas ukuran A4 (kuarto), kepadatan halaman yang rendah, penomoran yang jelas antara judul dan sub judul dan kejelasan baik materi maupun instruksi. Prastowo (2011) menyimpulkan LKS yang memiliki desain sulit dan rumit akan mengakibatkan pesetra didik sulit untuk memfokuskan perhatian.

Kemudian untuk model pengembangan desain LKS yaitu dengan model reconstruction atau rekontruksi. Menurut Devi, dkk (2009), LKS model rekontruksi memiliki kegiatan seperti melengkapi suatu tabel berdasarkan data yang diperoleh, baik dari pengamatan langsung atau grafik. Pembelajaran menggunakan LKS membantu siswa untuk mengkonstruksi pengetahuan ke dalam otak mereka melalui tahapan berpikir, yaitu mengamati, menganalisis kemudian menyimpulkan. Kegiatan mengamati karakter morfologi dari contoh tanaman obat yang didapat dari hasil eskplorasi merupakan usaha untuk membuat materi lebih bersifat konret. Selain itu, dibantu juga dengan pertanyaan analisis untuk mendorong siswa agar mampu menemukan konsep keanekargaman hayati tingkat jenis.

Kemudian LKS yang telah divalidasi diujicobakan pada siswa SMAN 1 Ketahun kelas $X$ dengan kelas yang disediakan yaitu kelas $X_{1}$ dengan jumlah siswa 21 siswa. Pemilihan kelas ini berdasarkan hasil ulangan yang telah dilaksanakan. Sehingga peneliti 
tidak melakukan pretest lagi untuk melihat kemampuan awal siswa namun langsung mengujicobakan LKS dan melakulan post test untuk melihat hasil belajar siswa apakah meningkat atau tidak. Setelah dilakukan post test diperoleh persentasi ketuntasan 90,47\%.

\section{KESIMPULAN DAN SARAN}

\section{Kesimpulan}

a) Desain LKS yang dikembangkan bentuknya lebih simple dari LKS sebelumnya. Meskipun simple LKS hasil pengembangan ini tidak melupakan prosedur dan struktur pembuatan LKS yang benar. LKS ini direspon baik oleh siswa dengan bukti bahwa hasil belajar siswa meningkat dan tuntas klasikal.

b) Penggunaan LKS berdasarkan hasil eksplorasi tanaman obat di desa Bukit Indah Kecamatan Ketahun dikatakan valid dengan rata-rata keseluruhan validasi LKS $88,53 \%$ dan dapat digunakan sebagai sumber belajar dengan hasil belajar siswa memperoleh rata-rata 92,38 dengan persentase ketuntasan secara klasikal $90,47 \%$ dikatakan tuntas.

c) Jenis tanaman obat yang dimanfaatkan oleh masyarakat desa Bukit Indah Kecamatan Ketahun terdapat 44 jenis tanaman obat tergolong dalam 25 famili dan famili tanaman yang paling banyak dimanfaatkan Zingiberaceae dengan jumlah 7 jenis.

\section{Saran}

1) Untuk peneliti selanjutnya diharapkan agar melakukan penelitian di daerah lain tentang eksplorasi tanaman obat apa saja yang dimanfaatkan supaya memperkaya pengetahuan jenisjenis tanaman obat yang belum terdata di skripsi sebelumnya sehingga terdapat data baru tentang jenis tanaman obat.

2) Diharapkan untuk melakukan penelitian lanjutan tentang pengimplementasian tidak hanya satu kelas tetapi menggunakan dua kelas untuk mengetahui perbedaan dari hasil belajar dan keefektifan dalam menggunakan LKS dalam pembelajaran.

\section{DAFTAR PUSTAKA}

Arikunto, Suharsimi. 2013. Prosedur Penelitian. Jakarta: Bineka Cipta

Devi, Poppy Kamala, Renny Sofiraeni, Khairuddin. 2009. Pengembangan Perangkat Pembelajaran. Jakarta: PPPPTK IPA.

Mulyasana, Dedi. 2012. Pendidikan Bermutu dan Berdaya Saing. Bandung:: Remaja Rosdakarya

Prastowo, A. 2011. Panduan Kreatif Membuat Bahan Ajar Inovatif. Jogyakarta:

Diva Press

Putra, Winkanda Satria. 2016. Kitab Herbal Nusantara. Yogyakarta: KATAHATI

Sugiyono. 2011. Metode Penelitian Kuantitatif Kualitatif dan $R \& D$. Bandung: Alfabeta

Sugiyono. 2016. Metode Penelitian \& Pengembangan Reseach and Development. Bandung: Alfabeta

Sukardi. 2012. Evaluasi Pendidikan Prinsip \& Operasionalnya. Jakarta : Bumi Aksara

Trianto. 2012. Model Pembelajaran Terpadu. Jakarta: PT Bumi Aksara 